\section{(A) Check for updates}

Cite this: Dalton Trans., 2021, 50, 5465

\title{
Hydrogen bonding to metals as a probe for an inverted ligand field $\uparrow$
}

\author{
Alberto Pérez-Bitrián, (D) Miguel Baya, (D) José M. Casas, (D) Antonio Martín (ID) and \\ Babil Menjón (D)*
}

Electron-rich, late transition metals are known to act as hydrogen-bonding ( $\mathrm{HBd})$ acceptors. In this regard, $\mathrm{Pt}($ II) centres in square-planar environments are particularly efficient. It is however puzzling that no convincing experimental evidence is currently available for the isoelectronic neighbour Au(III) being involved in $\mathrm{HBd}$ interactions. We report now on the synthesis and characterisation of two series of isoleptic and isoelectronic $\left(d^{8}\right)$ compounds $\left[\left(\mathrm{CF}_{3}\right)_{3} \mathrm{Pt}(\mathrm{L})\right]^{-}$and $\left(\mathrm{CF}_{3}\right)_{3} \mathrm{Au}(\mathrm{L})$, where the $\mathrm{L}$ ligands are based on the quinoline frame and have been selected to favour HBd with the metal centre. Strong HBd interactions were actually found in the $\mathrm{Pt}($ II) compounds, based on structural and spectroscopic evidence, and they were further confirmed by theoretical calculations. In contrast, no evidence was obtained in the Au(II) case. In order to find the reason underlying this general disparity, we undertook a detailed theoretical analysis of the model systems $\left[\left(\mathrm{CF}_{3}\right)_{3} \mathrm{Pt}\right.$ $(p y)]^{-}$and $\left(\mathrm{CF}_{3}\right)_{3} \mathrm{Au}(\mathrm{py})$. This study revealed that the filled $\mathrm{d}_{z^{2}}$ orbital is the HOMO in the case of Pt(II), but is buried in the lower energy levels in the case of $\mathrm{Au}($ III). The sharply different electronic configurations involve ligand-field inversion on going from Pt to the next element Au. This is not a gradual but an abrupt change, which invalidates $\mathrm{Au}(\mathrm{II})$ as a $\mathrm{HBd}$-acceptor wherever ligand-field inversion occurs.

Received 22nd February 2021 Accepted 16th March 2021

DOI: $10.1039 / \mathrm{d} 1 \mathrm{dt} 00597 \mathrm{a}$ rsc.li/dalton centres. ${ }^{4,5}$ In contrast, no conclusive evidence for the isoelectronic $\mathrm{Au}(\mathrm{III})$ centre acting as a HBd-acceptor has been found thus far despite colossal efforts currently invested in the development of gold chemistry. ${ }^{6}$ This failure is challenging and indicates that there might be a fundamental reason to rationalise it. Aiming to gain more insight into this puzzling subject, we present a comparative study of a simple system formed by two series of isoelectronic $\left(\mathrm{d}^{8}\right)$ and isoleptic compounds with formulae $\left[\left(\mathrm{CF}_{3}\right)_{3} \mathrm{Pt}(\mathrm{L})\right]^{-}$ and $\left(\mathrm{CF}_{3}\right)_{3} \mathrm{Au}(\mathrm{L})$. The ligands $\mathrm{L}$, based on the quinoline frame, are most suited to enable M...HE interactions, as previously demonstrated with $\mathrm{Pt}(\mathrm{II})$ centres in various other coordination environments. ${ }^{5 b, 7}$ Moreover, the small size of the $\mathrm{CF}_{3}$ groups should minimize the steric impact, thereby removing a potential biasing source. Thus, the overall molecular frame of our system has been so chosen as to allow and even favour intramolecular M $\cdots$ HE interactions. In the present study, a dual experimental and theoretical approach reveals that the dissimilar performances of $\mathrm{Pt}(\mathrm{II})$ and $\mathrm{Au}(\mathrm{III})$ as HBd-acceptors originate from their fundamentally different electronic structures. This evidences an essential disparity between apparently similar neighbouring elements.

\section{Results and discussion}

Zaragoza, Zaragoza, Spain. E-mail: b.menjon@csic.es

$\dagger$ Electronic supplementary information (ESI) available: Experimental details and additional figures (.pdf); atomic coordinates of the optimized structures (.xyz). CCDC 2040138-2040142. For ESI and crystallographic data in CIF or other electronic format see DOI: 10.1039/d1dt00597a

\section{Synthetic, structural and spectroscopic results}

Compound $\left[\mathrm{NBu}_{4}\right]\left[\left(\mathrm{CF}_{3}\right)_{3} \mathrm{Pt}(\mathrm{NCMe})\right]$ was prepared in solution as a convenient synthon of the anionic fragment $\left(\mathrm{CF}_{3}\right)_{3} \mathrm{Pt}^{\ominus}$ 


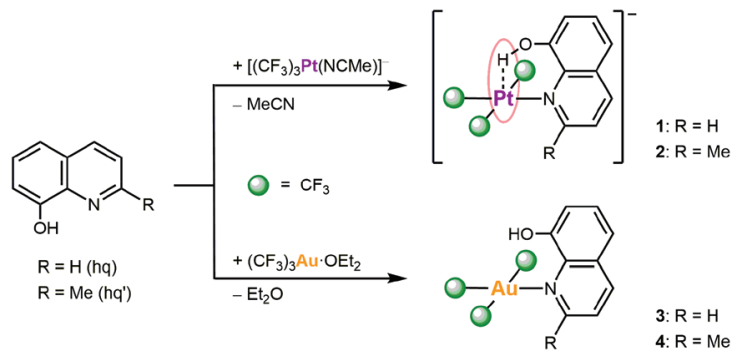

Scheme 1 Synthesis of compounds 1-4. Where appropriate, the cation is $\left[\mathrm{NBu}_{4}\right]^{+}$. See the $\mathrm{ESI} \dagger$ for details.

(see the Experimental section in the ESI $\dagger$ ). In this complex, the labile ligand MeCN was easily replaced by 8-hydroxyquinoline (hq) or 8-hydroxyquinaldine (hq') to afford the organoplatinum(II) derivatives $\left[\mathrm{NBu}_{4}\right]\left[\left(\mathrm{CF}_{3}\right)_{3} \mathrm{Pt}(\mathrm{hq})\right]$ (1) and $\left[\mathrm{NBu}_{4}\right]\left[\left(\mathrm{CF}_{3}\right)_{3} \mathrm{Pt}\right.$ $($ hq')] (2), respectively (Scheme 1). Compounds 1 and 2 were isolated in good yields as fairly stable white solids. They were found to exhibit strong Pt...HO intramolecular interactions as confirmed from a number of structural and spectroscopic studies, which will be presented next.

The crystal structure of 2 was determined by X-ray diffraction (XRD) methods. Reliable data obtained by low-tempera-
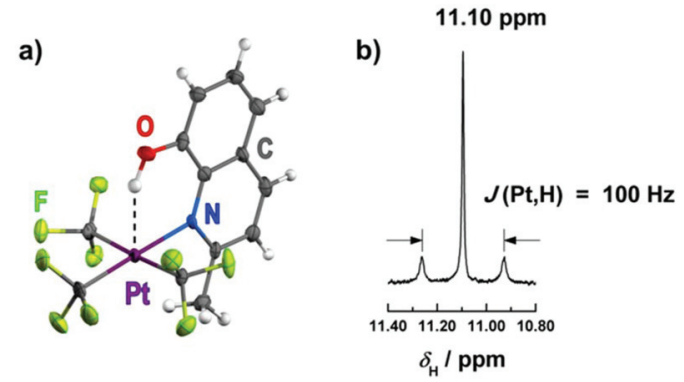

Fig. 1 (a) Displacement-ellipsoid diagram (50\% probability) of the $\left[\left(\mathrm{CF}_{3}\right)_{3} \mathrm{Pt}\left(\mathrm{hq}^{\prime}\right)\right]^{-}$anion as found in single crystals of 2; relevant structural parameters are given in Table 1. (b) ${ }^{1} \mathrm{H}$ NMR signal of the $\mathrm{OH}$ nucleus ( $300.130 \mathrm{MHz}, \mathrm{CD}_{2} \mathrm{Cl}_{2}, 253 \mathrm{~K}$ ) with spectral parameters indicated; the whole spectrum is shown in Fig. $\mathrm{S} 4 . \dagger$ ture diffraction on good-quality single crystals enabled us to locate the $\mathrm{OH}$ atom directly from the difference density maps and the position was refined freely using no constraints. In the final position, the $\mathrm{O}-\mathrm{H}$ vector is directed toward the $\mathrm{Pt}$ atom with a short $\mathrm{Pt} \cdots \mathrm{H}$ distance of $205(9) \mathrm{pm}$ and a Pt $\cdots \mathrm{H}-\mathrm{O}$ angle of $158(8)^{\circ}$ (Fig. 1a). The Pt...HO distance (Table 1) is comparable with that found in the related perfluorophenyl complex $\left[\mathrm{NBu}_{4}\right]\left[\left(\mathrm{C}_{6} \mathrm{~F}_{5}\right)_{3} \mathrm{Pt}\left(\mathrm{hq}^{\prime}\right)\right](219 \mathrm{pm})^{7}$ even though the $\mathrm{CF}_{3}$ group is more electronegative than $\mathrm{C}_{6} \mathrm{~F}_{5} .{ }^{8}$ The non-bonding Pt...O distances are indistinguishable in both cases: ca. $300 \mathrm{pm}$. Additional structural parameters in the crystal structure of 2 are unexceptional and in agreement with other complexes of the $\left(\mathrm{CF}_{3}\right)_{3}$ Pt moiety. ${ }^{9}$

The Pt...HO interaction found in the crystal structure of $\mathbf{2}$ is not merely due to crystal packing effects, since it is maintained in solution. In the ${ }^{1} \mathrm{H}$ NMR spectrum of 2 (Fig. 1b), the $\mathrm{OH}$ signal $\left(\delta_{\mathrm{H}}=11.10 \mathrm{ppm}\right)$ appears downfield shifted $\left(\Delta \delta_{\mathrm{H}}=\right.$ $2.8 \mathrm{ppm})$ with respect to the free ligand $\left(\delta_{\mathrm{H}}=8.3 \mathrm{ppm}\right) .{ }^{10}$ The sole signal shift might not be sufficient to prove the existence of HBd to the metal. ${ }^{11}$ However, the observed coupling between the involved atoms with a large coupling constant, $J\left({ }^{195} \mathrm{Pt}, \mathrm{H}\right)=100 \mathrm{~Hz}$, clearly shows that the Pt...HO interaction is preserved along the measuring process (NMR time scale, which is a fairly long one). The ${ }^{1} \mathrm{H}$ NMR spectrum of $\mathbf{1}$ is qualitatively similar (Fig. S2 $\dagger$ ). Thus, the $\mathrm{OH}$ signal is downfield shifted to roughly the same region $\left(\delta_{\mathrm{H}}=10.82 \mathrm{ppm}\right)$ and it also shows large coupling to platinum: $J\left({ }^{195} \mathrm{Pt}, \mathrm{H}\right)=82.7 \mathrm{~Hz}$, which can be taken as experimental evidence of mutual penetration of the two atoms involved. The ortho- $\mathrm{H}\left(\mathrm{H}^{o}\right)$ signal appearing at $\delta_{\mathrm{H}}=9.29 \mathrm{ppm}$ shows ${ }^{195} \mathrm{Pt}$-satellites as well. It must be noted that the splitting of this signal, ${ }^{3} J\left({ }^{195} \mathrm{Pt}, \mathrm{H}\right) \approx 25 \mathrm{~Hz}$, is much smaller than that observed in the $\mathrm{OH}$ signal, even though the latter is located 5 bonds apart from the metal centre $v s .3$ in the case of $\mathrm{H}^{o}$. The extra contribution can be assigned to the direct $\mathrm{Pt} \cdots \mathrm{H}-\mathrm{O}$ interaction.

The isoleptic and isoelectronic $\left(\mathrm{d}^{8}\right)$ organogold(III) compounds $\left(\mathrm{CF}_{3}\right)_{3} \mathrm{Au}(\mathrm{hq})(3)$ and $\left(\mathrm{CF}_{3}\right)_{3} \mathrm{Au}\left(\mathrm{hq} \mathrm{q}^{\prime}\right)(4)$ were prepared from the neutral solvate $\left(\mathrm{CF}_{3}\right)_{3} \mathrm{Au} \cdot \mathrm{OEt}_{2}{ }^{12}$ by using similar procedures to those mentioned above (Scheme 1) and were isolated in good yields as stable white solids. Our many attempts

Table 1 Relevant geometric parameters of the structurally characterised derivatives containing the isoelectronic $\left(\mathrm{CF}_{3}\right)_{3} \mathrm{M}$ fragments in this work $(\mathrm{M}=\mathrm{Pt}, \mathrm{Au} ; \mathrm{E}=\mathrm{C}, \mathrm{O})^{\mathrm{a}}$

\begin{tabular}{|c|c|c|c|c|c|c|c|}
\hline Compound & $\mathrm{M}-\mathrm{C}^{b} / \mathrm{pm}$ & av. $\mathrm{M}-\mathrm{C}_{2}{ }^{c} / \mathrm{pm}$ & $\mathrm{M}-\mathrm{N} / \mathrm{pm}$ & $\mathrm{M} \cdots \mathrm{E} / \mathrm{pm}$ & $\mathrm{E}-\mathrm{H} / \mathrm{pm}$ & $\mathrm{M} \cdots \mathrm{H} / \mathrm{pm}$ & $\sum<^{d} / 0$ \\
\hline$\left[\mathrm{NBu}_{4}\right]\left[\left(\mathrm{CF}_{3}\right)_{3} \mathrm{Pt}\left(\mathrm{hq}^{\prime}\right)\right](2)$ & $202.0(6)$ & $206.6(7)$ & $213.2(5)$ & $297.2(5)$ & $97(9)$ & 205(9) & $360.1(3)$ \\
\hline$\left[\mathrm{NBu}_{4}\right]\left[\left(\mathrm{C}_{6} \mathrm{~F}_{5}\right)_{3} \mathrm{Pt}\left(\mathrm{hq}^{\prime}\right)\right]^{a}$ & $200.8(5)$ & 206.1(5) & $212.6(4)$ & $297.5(4)$ & $82^{e}$ & $219^{\grave{e}}$ & $360.0(2)$ \\
\hline$\left(\mathrm{CF}_{3}\right)_{3} \mathrm{Au}\left(\mathrm{hq} \cdot \mathrm{OH}_{2}\right)\left(3 \cdot \mathrm{OH}_{2}\right)$ & 202.3(3) & $208.4(3)$ & $210.4(2)$ & $265.8(2)$ & $81.9(5)$ & $\complement^{f}$ & $360.01(13)$ \\
\hline$\left[\mathrm{NBu}_{4}\right]\left[\left(\mathrm{CF}_{3}\right)_{3} \mathrm{Pt}(\mathrm{mq})\right](5)$ & $199.9(8)$ & $205.7(8)$ & $212.7(7)$ & $309(1)$ & $98^{e}$ & $273^{e, g}$ & $360.3(3)$ \\
\hline$\left(\mathrm{CF}_{3}\right)_{3} \mathrm{Au}(\mathrm{mq})(\mathbf{6})$ & $202.9(3)$ & $208.9(3)$ & $211.2(3)$ & $305.1(3)$ & $98^{e}$ & $267^{e, g}$ & $360.04(13)$ \\
\hline
\end{tabular}

${ }^{a}$ The closely related compound $\left[\mathrm{NBu}_{4}\right]\left[\left(\mathrm{C}_{6} \mathrm{~F}_{5}\right)_{3} \mathrm{Pt}\left(\mathrm{hq}^{\prime}\right)\right]$ (see Ref. 7) is also included for comparison. ${ }^{b}$ The M-C distance trans to the neutral $\mathrm{N}$-donor ligand is indicated here. ${ }^{c}$ Average of the two independent $\mathrm{M}-\mathrm{C}$ bond lengths in a trans arrangement. ${ }^{d}$ Summation of all adjacent $\mathrm{E}-\mathrm{M}-$ $\mathrm{E}^{\prime}$ angles as a measure of planarity. ${ }^{e}$ No estimated experimental error is indicated here because the $\mathrm{H}$ position was refined under constraints. ${ }^{f}$ The $\mathrm{O}-\mathrm{H}$ unit interacts with a $\mathrm{R}_{2} \mathrm{O}$ molecule $(\mathrm{R}=\mathrm{Et}, \mathrm{H})$, where the $\mathrm{R}_{2} \mathrm{O} \cdots \mathrm{H}-\mathrm{O}$ angles amount to $178(6)^{\circ}$ and $176(4)^{\circ}$, respectively, and the $\mathrm{O} \cdots \mathrm{O}^{\prime}$ separation is 263.6(4) and 265.0(3) pm in each case. ${ }^{g}$ The closest $\mathrm{M} \cdots \mathrm{H}$ distance is indicated here. 
a)

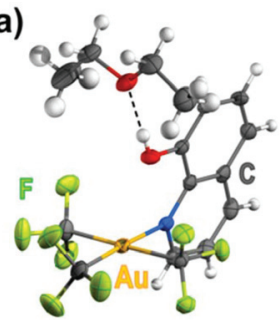

Fig. 2 Displacement-ellipsoid diagram (50\% probability) of the solvates 3. $\mathrm{OEt}_{2}$ (a) and $3 \cdot \mathrm{OH}_{2}$ (b). Relevant structural parameters are given in Table 1.

to obtain single crystals for XRD purposes under various conditions resulted in the formation of the solvates $3 \cdot \mathrm{OEt}_{2}$ and 3. $\mathrm{OH}_{2}$. Their molecular structures (Fig. 2) show that both the $\mathrm{Et}_{2} \mathrm{O}$ and $\mathrm{H}_{2} \mathrm{O}$ molecules act as HBd-acceptors with canonical, nearly linear $\mathrm{R}_{2} \mathrm{O} \cdots \mathrm{H}-\mathrm{O}$ arrangements $\left(>176^{\circ}\right.$; Table 1$)$. As a result, the $\mathrm{O}-\mathrm{H}$ vectors point away from the gold centre in an unusual s-trans conformation. Apart from this crucial difference, the remaining geometric features around the metal centre are very similar to those found in the Pt compound 2 described above. Compound $\mathbf{3} \cdot \mathrm{OH}_{2}$ lends experimental support to the monohydrate $\mathrm{hq} \cdot \mathrm{OH}_{2}$ in the less common strans conformation, which has been recently studied by calculation. ${ }^{13}$ The experimental separation between the oxygen atoms found in $3 \cdot \mathrm{OH}_{2}\left(\mathrm{O} \cdots \mathrm{O}^{\prime} 265.0(3) \mathrm{pm}\right)$ is substantially shorter than that calculated for hq. $\mathrm{OH}_{2}$ in the same conformation (O‥ $\left.\mathrm{O}^{\prime} 280.5 \mathrm{pm}\right)$, which implies a stronger HBd interaction in the organogold(III) complex.

In the absence of structural evidence, any spectroscopic information acquires particular relevance in order to decide on the existence of a possible $\mathrm{Au} \cdots \mathrm{HO}$ interaction. The IR spectra of 3 and 4 show sharp absorptions at 3581 and $3575 \mathrm{~cm}^{-1}$, respectively, with 19 and $14 \mathrm{~cm}^{-1}$ half-width values, which are due to $\nu(\mathrm{O}-\mathrm{H})$ vibrations (Fig. S18 and S19†). These high-frequency, sharp absorptions are characteristic of $\mathrm{OH}$ groups with little (if any) association. ${ }^{14}$ They appear well above the $\nu(\mathrm{O}-\mathrm{H})$ absorption observed for the free hq ligand both in dilute solutions in non-polar solvents $\left(3423-3400 \mathrm{~cm}^{-1}\right)^{13}$ and in the gas phase $\left(3462 \mathrm{~cm}^{-1}\right),{ }^{15}$ where intermolecular associations are minimized. It is worth noting that no absorption above $3000 \mathrm{~cm}^{-1}$ was, in turn, observed in the homologous Pt(II) complexes 1 and 2 (Fig. S16 and S17 $\dagger$ ). In the ${ }^{1} \mathrm{H}$ NMR spectra of compounds 3 and 4 (Fig. S6 and $\mathrm{S} 9 \dagger)$, the resonances corresponding to the hydroxyl groups appear as broad signals at $\delta_{\mathrm{H}}=7.03$ and 6.66 ppm, respectively, giving therefore no indication of the existence of any $\mathrm{Au} \cdots \mathrm{HO}$ interaction. However, the addition of $\mathrm{Et}_{2} \mathrm{O}$ to the samples under measurement produces dramatic downfield shifts of these signals to $\delta_{\mathrm{H}}>10 \mathrm{ppm}$ in both cases (Fig. S8 and $\mathrm{S} 11 \dagger$ ). The marked downfield shifts observed in the $\mathrm{OH}$ signals upon $\mathrm{Et}_{2} \mathrm{O}$ addition are in agreement with the $\mathrm{Et}_{2} \mathrm{O} \cdots \mathrm{HO}$ interaction detected in the solid state (Fig. 2a). It is clear that the $\mathrm{OH}$ groups in compounds $\mathbf{3}$ and $\mathbf{4}$ favour unsup-

ported intermolecular $\mathrm{HBd}$ interactions with peripheral $\mathrm{R}_{2} \mathrm{O}$ molecules $(\mathrm{R}=\mathrm{H}, \mathrm{Et})$ over the expected intramolecular $\mathrm{M} \cdots \mathrm{HO}$ interactions in analogy to the Pt homologues 1 and 2. This different behaviour will be studied by theoretical methods later on. It is worth noting that $\mathrm{Au} \cdots \mathrm{HE} \mathrm{HBd}$ interactions involving auride $\mathrm{Au}(-\mathrm{I})$ centres $^{16}$ or linear $\mathrm{d}^{10} \mathrm{Au}(\mathrm{I})$ complexes have been recently reported or predicted. ${ }^{17}$ The nature of related $\mathrm{Au} \cdots \mathrm{HE}$ interactions in gold clusters is still much debated. ${ }^{11 a, 18}$

The 8-methylquinoline (mq) ligand has the same skeleton as hq, but the $\mathrm{C}\left(\mathrm{sp}^{3}\right)-\mathrm{H}$ bond of the $\mathrm{CH}_{3}$ group is less polarized and therefore less prone to establish $\mathrm{HBd}$ interactions. Thus, a couple of compounds $\left[\mathrm{NBu}_{4}\right]\left[\left(\mathrm{CF}_{3}\right)_{3} \mathrm{Pt}(\mathrm{mq})\right](5)$ and $\left(\mathrm{CF}_{3}\right)_{3} \mathrm{Au}(\mathrm{mq})$ (6) was prepared as blank references following similar procedures to those mentioned above (see the Experimental section $\dagger$ ). They were characterised by XRD methods (Fig. 3).

In the solid state, the axial methyl groups take on a staggered conformation with respect to the metal and thus no $\mathrm{H}$ atom points directly to it. The associated $\mathrm{M} \cdots \mathrm{HC}\left(\mathrm{sp}^{3}\right)$ distances are 272.6/275.1 pm $(\mathrm{M}=\mathrm{Pt})$ and $266.5 / 276.0 \mathrm{pm}(\mathrm{M}=$ $\mathrm{Au}$ ), respectively. In our opinion, they are too long to evidence the existence of an intramolecular $\mathrm{M} \cdots \mathrm{HC}\left(\mathrm{sp}^{3}\right)$ interaction, considering that the sum of the corresponding van der Waals radii $(\mathrm{H}+\mathrm{M})$ amounts to $292(\mathrm{M}=\mathrm{Pt})$ and $286(\mathrm{M}=\mathrm{Au}) \mathrm{pm} \cdot{ }^{19}$ The remaining structural parameters around the metal including the non-bonding $\mathrm{M} \cdots \mathrm{C}\left(\mathrm{sp}^{3}\right)$ separation are indistinguishable within the experimental error (Table 1). In solution, there is no hint of hindered rotation of the methyl groups about the $\mathrm{C}\left(\mathrm{sp}^{3}\right)-\mathrm{C}\left(\mathrm{sp}^{2}\right)$ single bond. Thus, the $\mathrm{CH}_{3}$ signals in the ${ }^{1} \mathrm{H}$ and ${ }^{13} \mathrm{C}$ NMR spectra of compounds $5\left(\delta_{\mathrm{H}} / \delta_{\mathrm{C}}=3.83 / 22.7 \mathrm{ppm}\right)$ and $6\left(\delta_{\mathrm{H}} / \delta_{\mathrm{C}}=3.44 / 20.5 \mathrm{ppm}\right)$ appear as singlets and suffer only slight downfield shifts with respect to the free mq ligand $\left(\delta_{\mathrm{H}} / \delta_{\mathrm{C}}=2.83 / 18.15 \mathrm{ppm}\right) .{ }^{20}$ These moderate shifts may well be due to just anisotropic deshielding caused by the near metal centre. ${ }^{11}$ In fact, the couple 5 and 6 shows neither structural nor spectroscopic evidence for the existence of any substantial $\mathrm{M} \cdots \mathrm{HC}\left(\mathrm{sp}^{3}\right)$ interaction.

If we compare all the structural information presented in this work (Table 1), it becomes clear that the geometric arrangement of the ligands in the coordination plane shows
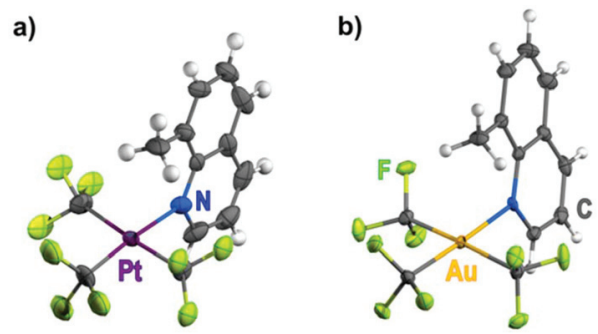

Fig. 3 Displacement-ellipsoid diagram (50\% probability) of the $\left[\left(\mathrm{CF}_{3}\right)_{3} \mathrm{Pt}\right.$ $(\mathrm{mq})]^{-}$(a) and $\left(\mathrm{CF}_{3}\right)_{3} \mathrm{Au}(\mathrm{mq})(\mathrm{b})$ entities as found in the single crystals of 5 and 6 , respectively. Only one set of rotationally disordered $\mathrm{CF}_{3}$ groups is shown in the Pt complex. Relevant structural parameters are given in Table 1. 
little variation within the whole series under study, with the major differences being observed along the axial direction. With the aim to decide on the nature of the M $\cdots \mathrm{HO}$ interaction in compounds 1-4 and to estimate the corresponding associated energy, we have carried out a number of theoretical studies, which will be presented next. Thus, we can benefit from the following advantageous features of our system: (1) the $\mathrm{Pt} / \mathrm{Au}$ pairs are isoleptic and isoelectronic; (2) the $\mathrm{CF}_{3}$ ligands are fairly small and can be suitably modelled; and (3) the molecular core of the quinoline ligands is quite rigid, which greatly reduces the number of variables.

\section{Energetics of the axial M*HO interaction}

Geometry optimizations at the DFT/M06 level were performed under no symmetry constraints. The final atomic coordinates are given in the ESI. $\dagger$ The calculated structure of the anion $\left[\left(\mathrm{CF}_{3}\right)_{3} \mathrm{Pt}\left(\mathrm{hq}^{\prime}\right)\right]^{-}$is in excellent agreement with that experimentally found in the crystal of 2 (Table S6 $\dagger$ ), which indicates that the observed Pt...HO interaction in 2 is not merely due to packing effects. The NMR data in solution clearly confirm this reasoning.

Once the geometries were optimized, we performed calculations of the overall energy of the $\left[\left(\mathrm{CF}_{3}\right)_{3} \mathrm{Pt}(\mathrm{hq})\right]^{-}$and $\left(\mathrm{CF}_{3}\right)_{3} \mathrm{Au}$ (hq) entities as a function of the $\mathrm{H}-\mathrm{O}-\mathrm{C}-\mathrm{C}$ torsion angle, $\tau$, in the coordinated hq ligand. Thus, a stepwise variation of $\tau$ was introduced as the only geometric constraint. The resulting energy profiles are represented in Fig. 4. It is clearly observed that the Pt...HO interaction is attractive and maximized at an optimal value of $\tau=0^{\circ}$ (Fig. 4a), which is close to the experi-

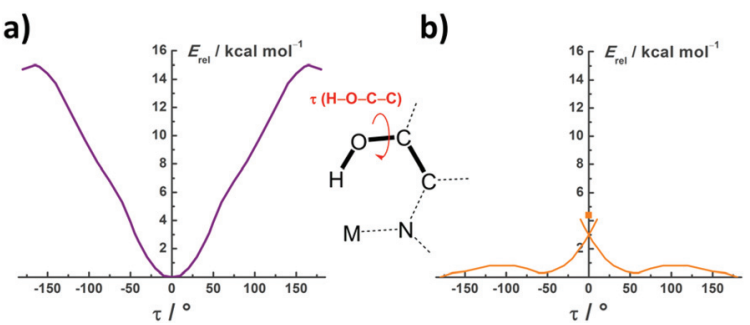

Fig. 4 Energy profiles obtained for $\left[\left(\mathrm{CF}_{3}\right)_{3} \mathrm{Pt}(\mathrm{hq})\right]^{-}$(a) and $\left(\mathrm{CF}_{3}\right)_{3} \mathrm{Au}(\mathrm{hq})$ (b) as a function of the $\mathrm{H}-\mathrm{O}-\mathrm{C}-\mathrm{C}$ torsion angle $\tau$. mental value found in the crystal of 2: $\tau=-7^{\circ}$. The energy difference between the minimum at $\tau=0^{\circ}$ and the rotamers at $\tau= \pm 180^{\circ}$ was calculated to be $\sim 15.0 \mathrm{kcal} \mathrm{mol}^{-1}$. This value gives a reasonable estimate of the Pt...HO bond strength: it is in the turning point from the so-called strong (4-15 kcal $\mathrm{mol}^{-1}$ ) to very strong (15-40 kcal mol${ }^{-1}$ ) HBd interactions. ${ }^{2 a}$

A similar profile might be expected for the isoelectronic $\mathrm{Au}(\mathrm{III})$ centre, perhaps with a weaker interaction since the oxidation-state increase on going from $\mathrm{Pt}(\mathrm{II})$ to $\mathrm{Au}(\mathrm{III})$ and the overall charge variation should result in diminished Lewis basicity of the HBd-acceptor site. ${ }^{21}$ As a matter of fact, in a recent study on the hydration of various Pt(II) substrates, it was found that not only the anionic $\left[\mathrm{Pt}(\mathrm{CN})_{4}\right]^{2-}$ or neutral trans$\mathrm{Cl}_{2} \mathrm{Pt}\left(\mathrm{NH}_{3}\right)$ (glycine) substrates, but also the dipositive cation $\left[\mathrm{Pt}\left(\mathrm{NH}_{3}\right)_{4}\right]^{2+}$, all favour $\mathrm{Pt} \cdots \mathrm{HOH}$ over $\mathrm{Pt} \cdots \mathrm{OH}_{2}$ interactions with the surrounding $\mathrm{H}_{2} \mathrm{O}$ molecules regardless of the 4-unit change in the overall charge. ${ }^{22}$ Similar results were further obtained in the aquation of neutral and cationic platinum anticancer drugs. ${ }^{23}$ In our case, however, a totally unexpected profile was obtained on going from Pt(II) to Au(III). As shown in Fig. $4 \mathrm{~b}$, the $\mathrm{Au} \cdots \mathrm{HO}$ interaction is clearly repulsive. In fact, the rotamer with the $\mathrm{OH}$ group pointing directly to the Au centre $\left(\tau=0^{\circ}\right)$ is a transition state and appears located +4.5 kcal $\mathrm{mol}^{-1}$ above the non-interaction level $\left(\tau= \pm 180^{\circ}\right)$. The waving shape of the profile at intermediate $\tau$ values is due to some tilting of the $\mathrm{O}-\mathrm{H}$ unit towards the nearest $\mathrm{F}$ atoms to establish weak $\mathrm{O}-\mathrm{H} \cdots \mathrm{F}$ contacts. This effect is also present in the Pt case, but is less noticeable in the corresponding profile (Fig. 4a).

The optimized compounds were further studied with the aid of Bader's quantum theory of atoms in molecules (QTAIM). ${ }^{24}$ The topological analysis of the electron density function $\rho(\mathbf{r})$ of the platinum compounds 1 and 2 (Fig. 5) shows bond paths (BPs) and bond critical points (BCPs) along the Pt...HO line, which are characteristic of a HBd interaction. $^{25}$ The corresponding $\rho(\mathbf{r})$ values (0.0401 and 0.0448; Table 2) are higher than those previously found in related systems. ${ }^{26}$ It is worth noting that the calculated Pt $\cdots \mathrm{H}$ bond length in the analysed entity 2 (205.5 pm) exactly matches with that experimentally found in the crystal: 205(9) pm (Table S6 $\dagger$ ). The penetration of the BCP into the Pt shell is also in accordance with the sizable internuclear $J\left({ }^{195} \mathrm{Pt}, \mathrm{H}\right)$ coupling experi-
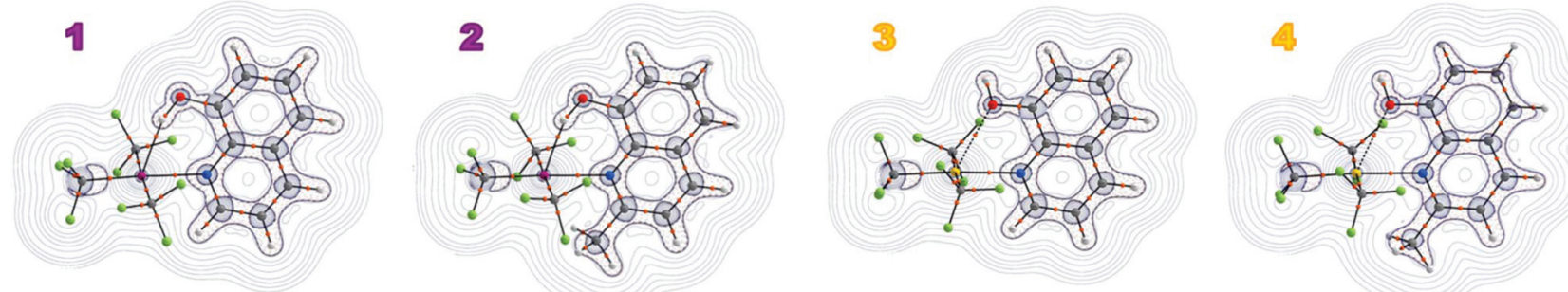

Fig. 5 2D contour-line $\nabla^{2} \rho(r)$ diagrams obtained from QTAIM analysis of the optimized compounds 1-4. Cross sections contain the Pt/Au, O and N atoms in each case. Bond critical points (orange spheres) and bond paths (black straight lines) are shown as obtained using weak-CP (0.03) and nonCP (0.02) thresholds. 
Table 2 Critical-point (CP) topology in the bond path (BP) between the interacting A and B atoms

\begin{tabular}{|c|c|c|c|c|c|c|}
\hline \multirow{2}{*}{$\begin{array}{l}\text { Complex } \\
\text { CP (A-B) }\end{array}$} & \multirow{2}{*}{$\begin{array}{l}1 \\
\mathrm{Pt}-\mathrm{H}\end{array}$} & \multirow{2}{*}{$\begin{array}{l}2 \\
\mathrm{Pt}-\mathrm{H}\end{array}$} & \multirow{2}{*}{$\begin{array}{l}3 \\
\mathrm{Au}-\mathrm{O}_{\mathrm{hq}}\end{array}$} & \multicolumn{2}{|l|}{$3 \cdot \mathbf{E t}_{2} \mathrm{O}$} & \multirow{2}{*}{$\begin{array}{l}\mathbf{4} \\
\mathrm{Au}-\mathrm{O}_{\mathrm{hq}^{\prime}}\end{array}$} \\
\hline & & & & $\mathrm{Au}-\mathrm{O}_{\mathrm{hq}}$ & $\mathrm{Et}_{2} \mathrm{O}-\mathrm{H}$ & \\
\hline$\rho(\mathbf{r}) / \mathrm{au}$ & 0.0401 & 0.0448 & 0.0243 & 0.0296 & 0.0533 & 0.0268 \\
\hline$\nabla^{2} \rho(\mathbf{r})$ & 0.0753 & 0.0830 & 0.0975 & 0.1230 & 0.1660 & 0.1107 \\
\hline Ellipticity & 0.021 & 0.022 & 0.111 & 0.112 & 0.029 & 0.123 \\
\hline $\mathrm{A}-\mathrm{B} / \mathrm{pm}$ & 210 & 205 & 273 & 264 & 163 & 268 \\
\hline BP length/pm & 214 & 208 & 273 & 264 & 166 & 268 \\
\hline$G(\mathbf{r}) / \mathrm{au}$ & 0.0251 & 0.0289 & 0.0230 & 0.0294 & 0.0429 & 0.0262 \\
\hline$V(\mathbf{r}) / \mathrm{au}$ & -0.0314 & -0.0369 & -0.0216 & -0.0281 & -0.0442 & -0.0247 \\
\hline$H(\mathbf{r}) / \mathrm{au}$ & -0.0063 & -0.0081 & 0.0014 & 0.0013 & -0.0013 & 0.0015 \\
\hline$G(\mathbf{r}) / \rho(\mathbf{r})$ & 0.63 & 0.64 & 0.95 & 0.99 & 0.80 & 0.98 \\
\hline
\end{tabular}

mentally observed in solution (see above). In the optimized minima of the gold compounds 3 and $\mathbf{4}$, the $\mathrm{OH}$ group points away from the metal centre, an arrangement which is obviously not suited for intramolecular $\mathrm{Au} \cdots \mathrm{HO}$ interactions. The topological analysis reveals, however, that a BP is located instead on the Au..O line (Fig. 5). This means that the gold centre acts rather as a Lewis acid along the axial direction. On the other hand, the topological analysis of the $3 \cdot \mathrm{OEt}_{2}$ adduct (Fig. S22 $\dagger$ ) confirmed the presence of a canonical intermolecular $\mathrm{O} \cdots \mathrm{HO}$ interaction, as experimentally observed in the solid state (Fig. 2a) and in solution (Fig. S8†). The positive values of $\nabla^{2} \rho(\mathbf{r})$ in all cases indicate that the HBd interactions are mainly electrostatic. However, the slightly negative values of the Pt...H local energy density function $H(\mathbf{r})$ in compounds $\mathbf{1}$ and $\mathbf{2}$ denote partial covalence, and the same applies to the $\mathrm{Et}_{2} \mathrm{O} \cdots \mathrm{HO}$ bond in the $3 \cdot \mathrm{OEt}_{2}$ adduct.

Up to this point, we have presented experimental and theoretical evidence demonstrating that the platinum compounds 1 and 2 exhibit strong M $\cdots$ HO interactions, whereas no evidence was found in the homologous gold compounds 3 and 4. We have also seen that compounds 1-4 show much structural resemblance in the coordination plane, but largely differ in the axial direction depending on the metal. All other factors being equal, the difference must rely on the metal itself.

\section{Inverted ligand field}

In order to ascertain the underlying reason for the substantial difference found between the Pt and Au couples under study, we analysed the electronic structures of the model compounds $\left[\left(\mathrm{CF}_{3}\right)_{3} \mathrm{Pt}(\mathrm{py})\right]^{-}(7)$ and $\left(\mathrm{CF}_{3}\right)_{3} \mathrm{Au}(\mathrm{py})(\mathbf{8})$, which have the same in-plane coordination skeleton as compounds $\mathbf{1 - 4}$, but no axial ligands. The molecular geometries of the model compounds 7 and 8 were optimized under imposed $C_{\mathrm{s}}$ symmetry (Fig. 6). Symmetrisation greatly simplifies the analysis of the electronic structures at a negligible energy cost $(\Delta E<1 \mathrm{kcal}$ $\left.\mathrm{mol}^{-1}\right)$. The obtained results are shown in Fig. 7.

In the platinum compound 7- $C_{\mathrm{S}}$ (Fig. 7, left), the energy levels with major metal contribution (purple labelling) roughly follow the standard splitting of the $d$ metal orbitals under a square-planar ligand field. ${ }^{27}$ Even in ideal $\mathrm{MX}_{4}$ entities with $D_{4 \mathrm{~h}}$ symmetry, the precise d-ordering depends on the metal

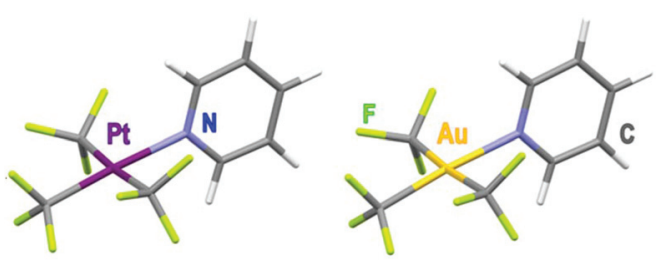

Fig. 6 Structures of the model compounds $\left[\left(\mathrm{CF}_{3}\right)_{3} \mathrm{Pt}(\mathrm{py})\right]^{-}\left(7-\mathrm{C}_{\mathrm{s}}\right)$ and $\left(\mathrm{CF}_{3}\right)_{3} \mathrm{Au}(\mathrm{py})\left(8-\mathrm{C}_{\mathrm{s}}\right)$ optimized at the DFT/M06 level under imposed $C_{\mathrm{s}}$ symmetry.

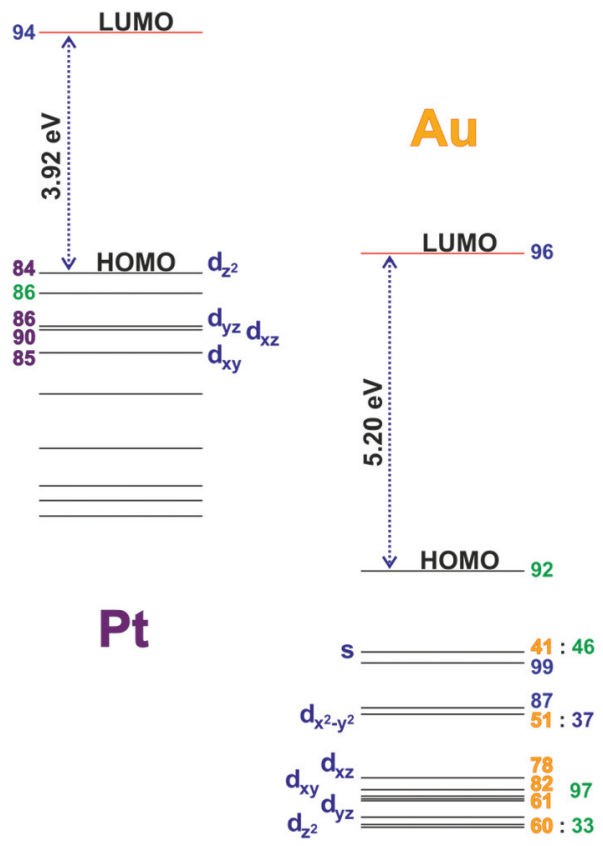

Fig. 7 Electronic structures of the model compounds 7- $C_{s}$ (left) and 8$C_{s}$ (right) obtained by calculation at the DFT/M06 level. Contributions to the most relevant MOs are indicated by the following colour code: $\mathrm{Pt}$ (purple), $\mathrm{Au}$ (golden), $\mathrm{CF}_{3}$ (green), and py (blue). See the $\mathrm{ESI} \uparrow$ for details.

ion and the type of ligand involved. ${ }^{27-29}$ In any case, the $\mathrm{d}_{x^{2}-y^{2}}$ orbital, which is oriented towards the ligands, is always greatly destabilized and remains empty in most $\mathrm{d}^{8}$ metal complexes. ${ }^{27}$ This is the case of complex $7-C_{\mathrm{s}}$, where the MO with main 
$\mathrm{d}_{x^{2}-y^{2}}$ contribution is located well above the LUMO. Here, the $\mathrm{d}_{x y}$ orbital appears twofold stabilized below the $\mathrm{d}_{x z}, \mathrm{~d}_{y z}$ orbitals. ${ }^{28 a, 29}$ Most importantly, $\mathrm{d}_{z^{2}}$ is always located in between and generally filled in $\mathrm{d}^{8}$ metal complexes. This is also the case of complex 7- $C_{\mathrm{s}}$, where the MO with main $\mathrm{d}_{z^{2}}$ contribution is identified as the HOMO (Fig. 8a).

In $\mathrm{d}^{8}$ metal complexes with a square-planar geometry, [M], the $\mathrm{d}_{z^{2}}$ orbital has suitable symmetry to interact along the axial direction with Lewis acids, A, wherever the energy balance is favourable. This dative $[\mathrm{M}] \rightarrow \mathrm{A}$ interaction was theoretically studied by Aullón and Álvarez, who scrutinized a wide range of cases and derived important consequences therefrom. ${ }^{30} \mathrm{~A}$ simple example is given with the $\mathrm{NO}^{+}$cation, which affords a number of $[\mathrm{M}] \rightarrow \mathrm{NO}$ metal nitrosyls. ${ }^{31}$ Cationic metal fragments, $\mathrm{QL}_{n}{ }^{q+}$, or simple metal cations $(n=0)$ with an obvious Lewis-acidic character are also known to enable manifold $[\mathrm{M}] \rightarrow \mathrm{A}$ interactions. ${ }^{32}$ Similar $[\mathrm{M}] \rightarrow \mathrm{X}_{2}$ interactions with halogens are key intermediates in $\mathrm{S}_{\mathrm{N}} 2$ oxidative-addition processes eventually affording $\mathrm{X}-[\mathrm{M}]-\mathrm{X}$ derivatives. ${ }^{33}$ The range of Lewis acids has been recently expanded to incorporate $\mathrm{EX}_{3}$ neutral molecules of Group 13 elements $(\mathrm{E}=\mathrm{B}, \mathrm{Al}, \mathrm{Ga} ; \mathrm{X}=\mathrm{H}, \mathrm{F}, \mathrm{Cl}$, $\mathrm{Br}) .{ }^{34}$ In the same way, the HOMO of $7-C_{\mathrm{S}}$ with main $5 \mathrm{~d}_{z^{2}}$ contribution is most suited to establish an axial Pt...HO interaction, ${ }^{35}$ as experimentally observed in compounds $\mathbf{1}$ and 2 . This Pt...HO interaction can be considered as an incipient stage in proton transfer from oxygen to the metal.

When we turn to the gold compound $8-C_{\mathrm{s}}$, a quite different electronic structure is found (Fig. 7, right). The observed difference is not just quantitative but essentially qualitative and evidences ligand-field inversion on going from $\mathrm{Pt}$ to $\mathrm{Au}$. The 'inverted ligand field' concept (ILF) has been only recently introduced. ${ }^{36}$ It is the last stage in the evolution of the ligand field theory along nearly a century. This theory, which had its origin in a purely ionic model (crystal field theory), ${ }^{37}$ later incorporated the tools of the MO theory, thereby enabling some degree of covalence in the chemical bonding between the central metal ion and the surrounding ligands. ${ }^{38}$ Now, the term ILF is coined ${ }^{36}$ to convey that the MOs with major metal $\mathrm{d}$ contribution are not at the frontier, as is usually the case (e.g. 7- $C_{\mathrm{s}}$ ), but submerged in the low energy levels of bonding MOs. This phenomenon was first identified in the organocopper(III) complex $\left[\mathrm{Cu}\left(\mathrm{CF}_{3}\right)_{4}\right]^{-}$and is also found in the heaviermetal homologues $\left[\mathrm{Ag}\left(\mathrm{CF}_{3}\right)_{4}\right]^{-}$and $\left[\mathrm{Au}\left(\mathrm{CF}_{3}\right)_{4}\right]^{-39}$ as well as in other high-valent late-TM derivatives with a high degree of covalency. ${ }^{36}$ The electronic structure variations found in
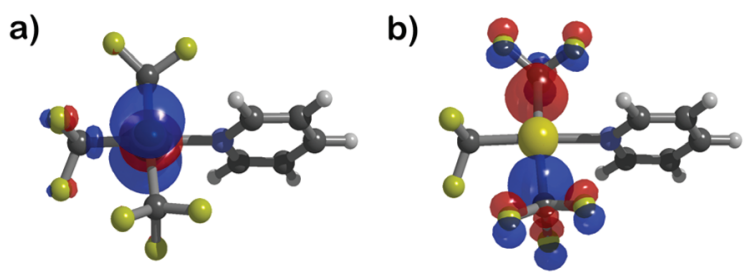

Fig. 8 HOMO of the model compounds $7-C_{s}$ (a) and $8-C_{s}$ (b) as obtained at the DFT/M06 level of calculation. simple halide complexes, such as $\left[\mathrm{PtBr}_{4}\right]^{2-}$ vs. $\left[\mathrm{AuBr}_{4}\right]^{-40}$ might also be taken as an indication of the ILF.

We would like to emphasize that covalency is a key factor determining ligand-field inversion. In the traditional ligand field theory, covalency has always been treated as a perturbative effect operating upon the main d-orbital splitting caused by the L ligands considered as ions or dipoles. The ILF phenomenon appears when the covalency of the $\mathrm{M}-\mathrm{L}$ bonds becomes so marked that it can no longer be treated just as a perturbation. In those cases, the metal d orbitals make a significant and even predominant contribution to the low-lying bonding MOs, which are otherwise contributed mainly by the ligands. The $\mathrm{M}-\mathrm{L}$ bond covalency is favoured with increasing electronegativity of the metal. In this regard, it cannot be overlooked that gold is the most electronegative metal ${ }^{41}$ and therefore more likely to form $\mathrm{M}-\mathrm{L}$ bonds with a higher degree of covalency. Accordingly, the bonding MO with major $5 \mathrm{~d}_{z^{2}}$ contribution in the gold compound $8-C_{\mathrm{s}}$ appears buried well below the HOMO, which is now centred on the mutually transstanding $\mathrm{CF}_{3}$ groups (Fig. 8b). This considerable energy lowering makes the $d_{z^{2}}$ unsuited for axial interaction with any Lewis acid in general, and with a polarized $\mathrm{OH}^{\delta+}$ unit in particular. This electronic arrangement seriously limits the role of $\mathrm{Au}(\mathrm{III})$ as a HBd-acceptor and provides a convincing explanation for our experimental observations.

\section{Conclusions}

In this work, the isoleptic and isoelectronic compounds $\left[\left(\mathrm{CF}_{3}\right)_{3} \mathrm{Pt}(\mathrm{L})\right]^{-}$and $\left(\mathrm{CF}_{3}\right)_{3} \mathrm{Au}(\mathrm{L})$ containing $\mathrm{L}$ ligands with the rigid quinoline skeleton have been prepared: 1-4 (Scheme 1). They are sensitive touchstones to assay the extent to which the isoelectronic $\mathrm{d}^{8}$ centres $\mathrm{Pt}$ (II) and $\mathrm{Au}(\mathrm{III})$ may act as HBd-acceptors. Using a combined experimental and theoretical approach, we demonstrate that the Pt...HO interactions detected in compounds $\mathbf{1}$ and $\mathbf{2}$ match every geometry and energy requirement stipulated for a genuine $\mathrm{HBd} .{ }^{1}$ Conversely, none of them is fulfilled in the gold compounds 3 and 4. As a matter of fact, the corresponding $\mathrm{Au} \cdots \mathrm{HO}$ interaction is found to be repulsive in nature (Fig. 4b). The origin of this disparity was found in the sharply different electronic structures of the model compounds $\left[\left(\mathrm{CF}_{3}\right)_{3} \mathrm{Pt}(\mathrm{py})\right]^{-}$and $\left(\mathrm{CF}_{3}\right)_{3} \mathrm{Au}(\mathrm{py})$ (Fig. 7). The electronic structure of the $\mathrm{Pt}(\mathrm{II})$ complex follows the standard sequence expected for $\mathrm{a} \mathrm{d}^{8}$ transition metal in a squareplanar environment. In contrast, the Au(III) homologous compound exhibits ligand-field inversion. The energy drop of the MO with major $5 \mathrm{~d}_{z^{2}}$ contribution greatly diminishes the axial basicity of $\mathrm{Au}(\mathrm{III})$ and invalidates it as a HBd-acceptor. It further limits the reactivity of $\mathrm{Au}(\mathrm{III})$ towards electrophiles. In fact, the Au(III) centre should rather behave as a Lewis acid and react preferentially with nucleophiles along the axial direction.

The drastic alteration in the electronic structure found here on going from Pt to Au was totally unexpected for contiguous transition metals and points to a deep break between elements of Groups 10 and 11. This fundamental disparity had been 
hitherto overlooked, probably because of the apparent structural similarity generally found between Pt(II) and Au(III) complexes, as in compounds 5 and $\mathbf{6}$ (Fig. 3). The chemistry of gold might therefore be determined not only by the wellknown relativistic effect, ${ }^{42}$ but also by the inverted ligand field (ILF) phenomenon. ${ }^{36}$ The consequences of ILF on reactivity are just starting to emerge.

\section{Conflicts of interest}

There are no conflicts to declare.

\section{Acknowledgements}

This work is dedicated to Prof. Dr. Santiago Alvarez on the occasion of his 70th birthday in recognition of his enlightening contributions to the most diverse chemistry concepts. This work was supported by the Spanish MICIU/FEDER (Project PGC2018-094749-B-I00) and the Gobierno de Aragón (Grupo E17_20R). BIFI (Instituto de Biocomputación y Física de Sistemas Complejos) and CESGA (Centro de Supercomputación de Galicia) are acknowledged for allocation of computational resources. A. P.-B. also thanks the Spanish Ministerio de Educación, Cultura y Deporte for a grant (FPU15/03940).

\section{Notes and references}

1 (a) G. R. Desiraju, Angew. Chem., Int. Ed., 2011, 50, 52; (b) E. Arunan, G. R. Desiraju, R. A. Klein, J. Sadlej, S. Scheiner, I. Alkorta, D. C. Clary, R. H. Crabtree, J. J. Dannenberg, P. Hobza, H. G. Kjaergaard, A. C. Legon, B. Mennucci and D. J. Nesbitt, Pure Appl. Chem., 2011, 83, 1637; (c) E. Arunan, G. R. Desiraju, R. A. Klein, J. Sadlej, S. Scheiner, I. Alkorta, D. C. Clary, R. H. Crabtree, J. J. Dannenberg, P. Hobza, H. G. Kjaergaard, A. C. Legon, B. Mennucci and D. J. Nesbitt, Pure Appl. Chem., 2011, 83, 1619.

2 (a) G. R. Desiraju and T. Steiner, The Weak Hydrogen Bond, Oxford University Press, 1999, sect. 3.5.1, pp. 271-277; (b) I. Alkorta, I. Rozas and J. Elguero, Chem. Soc. Rev., 1998, $27,163$.

3 (a) H. Schmidbaur, Angew. Chem., Int. Ed., 2019, 58, 5806;

(b) L. R. Falvello, Angew. Chem., Int. Ed., 2010, 49, 10045;

(c) M. J. Calhorda, in Hydrogen Bonding-New Insights, ed.

S. J. Grabowski, Springer, 2006, ch. 6, pp. 245-262;

(d) L. Brammer, Dalton Trans., 2003, 3145; (e) A. Martín, J. Chem. Educ., 1999, 76, 578.

4 (a) J. Kozelka, in Noncovalent Forces, ed. S. Scheiner, Springer, 2015, ch. 6, pp. 129-158; (b) I. C. M. WehmanOoyevaar, D. M. Grove, H. Kooijman, P. van der Sluis, A. L. Spek and G. van Koten, J. Am. Chem. Soc., 1992, 114, 9916; (c) L. Brammer, J. M. Charnock, P. L. Goggin, R. J. Goodfellow, A. G. Orpen and T. F. Koetzle, J. Chem.
Soc., Dalton Trans., 1991, 1789; (d) L. Brammer, J. M. Charnock, P. L. Goggin, R. J. Goodfellow, T. F. Koetzle and A. G. Orpen, J. Chem. Soc., Chem. Commun., 1987, 443; (e) A. Albinati, C. G. Anklin and P. S. Pregosin, Inorg. Chim. Acta, 1984, 90, L37.

5 (a) A. Behnia, M. A. Fard, P. D. Boyle and R. J. Puddephatt, Eur. J. Inorg. Chem., 2019, 2899; (b) M. Baya, U. Belío and A. Martín, Inorg. Chem., 2014, 53, 189; (c) S. Rizzato, J. Bergès, S. A. Mason, A. Albinati and J. Kozelka, Angew. Chem., Int. Ed., 2010, 49, 7440.

6 (a) Thematic Issue Chem. Rev., 2021, 121, still in preparation; (b) I. Chambrier, D. L. Hughes, R. J. Jeans, A. J. Welch, P. H. M. Budzelaar and M. Bochmann, Chem. Eur. J., 2020, 26, 939; (c) H. G. Raubenheimer and H. Schmidbaur, J. Chem. Educ., 2014, 91, 2024; (d) H. Schmidbaur, H. G. Raubenheimer and L. Dobrzańska, Chem. Soc. Rev., 2014, 43, 345; (e) F. Kraus, H. Schmidbaur and S. S. Al-juaid, Inorg. Chem., 2013, 52, 9669; (f) M. A. Cinellu, A. Zucca, S. Stoccoro, G. Minghetti, M. Manassero and M. Sansoni, J. Chem. Soc., Dalton Trans., 1995, 2865; $(g)$ M. A. Cinellu, A. Zucca, S. Stoccoro, G. Minghetti, M. Manassero and M. Sansoni, J. Chem. Soc., Dalton Trans., 1996, 4217.

7 J. M. Casas, L. R. Falvello, J. Forniés, A. Martín and A. J. Welch, Inorg. Chem., 1996, 35, 6009.

8 M. A. García-Monforte, S. Martínez-Salvador and B. Menjón, Eur. J. Inorg. Chem., 2012, 4945.

9 S. Martínez-Salvador, J. Forniés, A. Martín, B. Menjón and I. Usón, Chem. - Eur. J., 2013, 19, 324.

10 SDBS-1559, SDBSWeb: https://sdbs.db.aist.go.jp/sdbs/cgibin/landingpage?sdbsno=1559.

11 (a) J. Vícha, C. Foroutan-Nejad and M. Straka, Nat. Commun., 2019, 10, 1643; (b) S. Scheiner, ChemPhysChem, 2016, 17, 2263; (c) A. D. Buckingham and P. J. Stephens, J. Chem. Soc., 1964, 4583.

12 A. Pérez-Bitrián, M. Baya, J. M. Casas, L. R. Falvello, A. Martín and B. Menjón, Chem. - Eur. J., 2017, 23, 14918.

13 M. Amati, S. Belviso, P. L. Cristinziano, C. Minichino, F. Lelj, I. Aiello, M. la Deda and M. Ghedini, J. Phys. Chem. A, 2007, 111, 13403.

14 E. Pretsch, P. Bühlmann and M. Badertscher, Spektroskopische Daten zur Strukturaufklärung organischer Verbindungen, Springer, 6th edn, 2020, sect. 7.8.1, pp. 325-326.

15 G. N. Rodionova, Y. G. Tuchin and N. A. Partalla, Chem. Heterocycl. Compd., 1987, 23, 547.

16 E. S. Kryachko, J. Mol. Struct., 2008, 880, 23.

17 (a) X. Lin and Y. Mo, Inorg. Chem., 2021, 60, 460; (b) M. K. Pandey, H. S. Kunchur, D. Mondal, L. Radhakrishna, B. S. Kote and M. S. Balakrishna, Inorg. Chem., 2020, 59, 3642; (c) M. Kumar and J. S. Francisco, J. Am. Chem. Soc., 2020, 142, 6001; (d) S. K. Verma, S. N. Ansari, P. Kumari and S. M. Mobin, Organometallics, 2019, 38, 2591; (e) M. Straka, E. Andris, J. Vícha, A. Rưžička, J. Roithová and L. Rulíšek, Angew. Chem., Int. Ed., 2019, 58, 2011; $(f)$ M. Rigoulet, S. Massou, 
E. D. S. Carrizo, S. Mallet-Ladeira, A. Amgoune, K. Miqueu and D. Bourissou, Proc. Natl. Acad. Sci. U. S. A., 2019, 116, 46; (g) R. J. F. Berger, J. Schoiber and U. Monkowius, Inorg. Chem., 2017, 56, 956; (h) M. Teci, E. Brenner, D. Matt, C. Gourlaouen and L. Toupet, Chem. - Eur. J., 2015, 21, 10997. 18 (a) L. Estévez, Dalton Trans., 2020, 49, 4797; (b) M. A. Bakar, M. Sugiuchi, M. Iwasaki, Y. Shichibu and K. Konishi, Nat. Commun., 2017, 8, 576.

19 A. Bondi, J. Phys. Chem., 1964, 68, 441.

20 SDBS-1834, SDBSWeb: https://sdbs.db.aist.go.jp/sdbs/cgibin/landingpage?sdbsno=1834.

21 O. Kroutil, M. Předota and Z. Chval, Inorg. Chem., 2016, 55, 3252.

22 S. Aono, T. Mori and S. Sakaki, J. Chem. Theory Comput., 2016, 12, 1189.

23 T. Hirakawa, D. R. Bowler, T. Miyazaki, Y. Morikawa and L. A. Truflandier, J. Comput. Chem., 2020, 41, 1973.

24 The Quantum Theory of Atoms in Molecules, ed. C. F. Matta and R. J. Boyd, Wiley-VCH, 2007.

25 W. D. Arnold and E. Oldfield, J. Am. Chem. Soc., 2000, 122, 12835.

26 F. Groenewald, H. G. Raubenheimer, J. Dillena and C. Esterhuysen, Dalton Trans., 2017, 46, 4960 see also ref. $4 a$ and $18 a$.

27 H. B. Gray, Transition Met. Chem., Ser. Adv., 1965, 1, 239.

28 (a) J. J. Oppenheim, B. J. McNicholas, J. Miller and H. B. Gray, Inorg. Chem., 2019, 58, 15202; (b) H. B. Gray and C. J. Ballhausen, J. Am. Chem. Soc., 1963, 85, 260.

29 J. Börgel, M. G. Campbell and T. Ritter, J. Chem. Educ., 2016, 93, 118.

30 G. Aullón and S. Alvarez, Inorg. Chem., 1996, 35, 3137.

31 (a) I. Ara, J. Forniés, M. A. García-Monforte, B. Menjón, R. M. Sanz-Carrillo, M. Tomás, A. C. Tsipis and C. A. Tsipis, Chem. - Eur. J., 2003, 9, 4094; (b) J. Forniés, B. Menjón, R. M. Sanz-Carrillo and M. Tomás, Chem. Ber., 1994, 127, 651; (c) R. Usón, J. Forniés, M. Tomás, B. Menjón, R. Bau, K. Sünkel and E. Kuwabara, Organometallics, 1986, 5, 1576.

32 (a) R. J. Puddephatt, J. Organomet. Chem., 2017, 849-850, 268; (b) M. Baya, Ú. Belío, I. Fernández, S. Fuertes and
A. Martín, Angew. Chem., Int. Ed., 2016, 55, 6978; (c) J. Forniés and A. Martín, in Metal Clusters in Chemistry, Vol. 1: Molecular Metal Clusters, ed. P. Braunstein, L. A. Oro and P. R. Raithby, Wiley-VCH, 1999, ch. 1.22, pp. 417-443; (d) R. Usón and J. Forniés, Inorg. Chim. Acta, 1992, 198-200, 165.

33 (a) D. W. Shaffer, S. A. Ryken, R. A. Zarkesh and A. F. Heyduk, Inorg. Chem., 2012, 51, 12122; (b) B. Menjón, S. Martínez-Salvador, M. A. Gómez-Saso, J. Forniés, L. R. Falvello, A. Martín and A. Tsipis, Chem. - Eur. J., 2009, 15, 6371; (c) L. M. Rendina and R. J. Puddephatt, Chem. Rev., 1997, 97, 1735.

34 Z. Chval, O. Dvořáčková, D. Chvalová and J. V. Burda, Inorg. Chem., 2019, 58, 3616.

35 R. Sánchez-de-Armas and M. S. G. Ahlquist, Phys. Chem. Chem. Phys., 2015, 17, 812.

36 R. Hoffmann, S. Alvarez, C. Mealli, A. Falceto, T. J. Cahill III, T. Zeng and G. Manca, Chem. Rev., 2016, 116, 8173.

37 H. Bethe, Ann. Phys., 1929, 395, 133.

38 (a) B. N. Figgis and M. A. Hitchman, Ligand Field Theory and Its Applications, Wiley-VCH, 2000; (b) C. J. Ballhausen, Introduction to Ligand Field Theory, McGraw-Hill, 1962; (c) J. S. Griffith and L. E. Orgel, Q. Rev., Chem. Soc., 1957, 11, 381.

39 M. Baya, D. Joven-Sancho, P. J. Alonso, J. Orduna and B. Menjón, Angew. Chem., Int. Ed., 2019, 58, 9954.

40 (a) W.-L. Li, Y. Li, C.-Q. Xu, X.-B. Wang, E. Vorpagel and J. Li, Inorg. Chem., 2015, 54, 11157; (b) Y. M. Bosworth and R. J. H. Clark, J. Chem. Soc., Dalton Trans., 1975, 381; (c) W. R. Mason III and H. B. Gray, Inorg. Chem., 1968, 7, 55.

41 P. Schwerdtfeger, O. R. Smits and P. Pyykkö, Nat. Rev. Chem., 2020, 4, 359.

42 (a) P. Pyykkö, Annu. Rev. Phys. Chem., 2012, 63, 45; (b) P. Schwerdtfeger and M. Lein, in Gold Chemistry: Applications and Future Directions in the Life Sciences, ed. F. Mohr, Wiley-VCH, 2009, ch. 4, pp. 183-247; (c) P. Schwerdtfeger, Heteroat. Chem., 2002, 13, 578; (d) N. Bartlett, Gold Bull., 1998, 31, 22. 